\title{
Mapping (Un)Common Space of Ethical Gradualism in the Era of the Anthropocene
}

\author{
SILVIYA SERAFIMOVA \\ Institute for the Study of Societies and Knowledge, \\ Bulgarian Academy of Sciences \\ silvija_serafimova@yahoo.com
}

\begin{abstract}
One of the main objectives of this article is to clarify how - taking into account that mapping (un)common worlds into one (un)common space is not an axiologically neutral process - one can avoid the pitfalls of thinking by adopting "either or" thinking modes, i.e. one can avoid choosing either radical anthropocentrism or radical eco-centrism as a starting point when mapping space in the era of the Anthropocene. In this context, I raise a hypothesis that such a methodological shift is possible if one succeeds, by developing some moral capacities, in applying the principle of ethical gradualism into an interspecies context.
\end{abstract}

KEYWORDS: ethical gradualism; proto-sympathetic empathy; sympathy; interspecies co-existence; mapping space

\section{Introduction}

Tackling the problem of living with or without others is one of the most demanding challenges for humans in the era of the Anthropocene. This challenge results from the fact that arguing for co-existing with other beings rather than existing among them in one (un)common space is not an axiologically neutral process. Furthermore, mapping space can never be considered as a matter of delineating the boundaries of a physical space alone, but also as requiring one to take a moral responsibility for those who inhabit the space in question. In turn, revealing the process of mapping as being based 
upon a particular type of moral mapping necessitates going beyond the idea of one absolutized common world and many disconnected uncommon worlds. A crucial reason for questioning the aforementioned idea comes from the need to clarify how humans, as moral agents, should feel obliged to morally respond on behalf of other beings which cannot act morally by themselves.

\subsection{Key Concepts and Clarifications}

In this article, my primary objective is to analyze how one can map a new space of coexistence by applying the principle of ethical gradualism and developing some moral capacities. The space in question is interpreted as an (un)common space which can non-contradictorily shelter many (un)common worlds. On a macro-methodological level, I aim to demonstrate how adopting the principle of ethical gradualism in an interspecies context can provide us with some alternatives to the mapping process which used to be based upon the value-loaded center-periphery dichotomy.

However, exploring the role of ethical gradualism requires clarifying what one understands by the term, since it is used in different fields of applied ethics. In this article, the introduction of the concept of ethical gradualism has to do with encouraging humans, as moral agents, to cultivate their sensitivity in treating other beings by substantially reducing the risk of moral arbitrariness in the decision-making process. In most fields of applied ethics (specifically in business ethics and medical ethics), the concept of ethical gradualism is broadly used for the purposes of differentiating between degrees of development or perfection (as in considering ethical culture in the field of business ethics) (Francis \& Murfey 2015), or for differentiating moral status (as in examining when and how embryos gain a moral status) (Francis, Gius \& Coin 2004). In this article, however, I adopt another, more detailed definition of ethical gradualism. This particular definition demonstrates how moral interactions between humans and other species can be enriched by going beyond the thinking mode of choosing either radical anthropocentrism or radical eco-centrism.

Analyzing how ethical gradualism can contribute to rebuilding the relationships between humans and the representatives of other species in moral terms requires conducting a two-step analysis. Firstly, one should reveal the methodological disadvantages not only of adopting radical anthropocentrism but also of adopting radical eco-centrism, and secondly, one should explore how choosing a particular type of ethical gradualism can positively affect the development of some moral capacities such as empathy and sympathy in an interspecies context. 
Regarding the first step of the analysis in question, I argue that radical anthropocentrism can be overcome by justifying moderate ethical anthropocentrism as grounded in the principle of ethical gradualism. What I understand by radical anthropocentrism partly corresponds with Bryan Norton's definition of strong anthropocentrism. According to Norton, "a value theory is strongly anthropocentric if all value countenanced by it is explained by reference to satisfactions of felt preferences of human individuals" (Norton $1984,134)$. In this context, giving priority to the concept of radical anthropocentrism over that of strong anthropocentrism is based upon the specification that the satisfaction of every single individual desire or need does not necessarily result in harming environment, as argued by Norton when defining strong anthropocentrism (ibid.). That is why one should first clarify which value of what desire leads to harming environment.

Grounding the introduction of a certain type of moderate ethical anthropocentrism, I refer to Arnold Burms' theory that "the morally most troubling aspect of anthropocentrism is not so much its assumption that humans are superior to non-humans, but that what matters to human beings is true in an absolute sense" (Burms in Drenthen 2011, 152). That is why one of the methodological benefits of applying moderate ethical anthropocentrism can be found in the way in which it puts in question not the felt individual preferences as such, but their absolute value.

It is the necessity of rethinking the role of absolute value that makes me argue for extending Norton's concept of weak anthropocentrism with that of moderate ethical anthropocentrism by adopting the principle of ethical gradualism. According to Norton, "a value theory is weakly anthropocentric if all value countenanced by it is explained by reference to satisfaction of some felt preference of a human individual or by reference to its bearing upon the ideals which exist as elements in a world view essential to determinations of considered preferences" (Norton 1984, 134). "A considered preference" is a desire or need which is consistent with a "rationally adopted world view - a world view which includes fully supported scientific theories and a metaphysical framework interpreting these theories, as well as a set of rationally supported aesthetic and moral ideals" (ibid.).

My main methodological concern about Norton's definition of the aforementioned preference is that, generally speaking, there is no contradiction in interpreting a given "considered" preference as both rationally justifiable and absolute in a moral sense, nor is there a functional problem in regarding some moral ideals as absolute.

However, what could be borrowed from Norton's definition of weak anthropocentrism for the purposes of enriching the application of moderate ethical anthropocentrism is the way in which nature can be anticipated as a valuable source for cultivat- 
ing moral sensitivity. According to Norton, if environmentalists can show that "values are formed and informed by contact with nature, nature takes on value as a teacher of human values" (ibid., 135). ${ }^{1}$

In turn, arguing for moderate ethical anthropocentrism, which is grounded in a certain type of ethical gradualism, contributes to revealing why favoring radical ecocentrism also raises some serious moral issues in an interspecies context. By radical eco-centrism I understand eco-centric theories which not only underrate the intrinsic value of human species, but also treat humans as a threat to the planet, which leads to advocating more extreme methods for preventing environmental destruction (Liddick 2006). What can be described as problematic in applying these methods is the way in which the destruction exerted on behalf of nature is morally justified by ascribing a moral value to human destruction (Begley 2009).

Going back to the second step of my analysis, namely, how a given type of ethical gradualism can contribute to the development of certain moral capacities in an interspecies context, requires specifying what this particular ethical gradualism should look like, as well as which human capacities can improve human interaction with nonhuman beings in moral terms.

By ethical gradualism I understand what Gunnar Skirbekk describes as a principle of "advocatory" representation. It concerns the way in which one takes moral responsibility in some borderline cases when given members of the human species should represent other humans or non-humans on their behalf in a fairly moral manner (Skirbekk 1994, 81-82). If, however, gradualism entails this application of the principle of "advocatory" representation, which is based upon acting morally on others' behalf, the question is how, in acting on others' behalf, one can feel obliged to act for the sake of those others. Clarifying the latter issue raises the need to elaborate upon the application of ethical gradualism with respect to some specific moral capacities, which can encourage one to value another's good as a matter of developing concern for the other for the other's own sake. Such capacities include, as I will point out, different types of empathy and sympathy, which contribute to outlining the role of moral agents' complex (moral) motivation.

Analyzing these types of empathy and sympathy raises at least two methodological difficulties. Firstly, some definitions of sympathy used to be applied to empathy

1 Another comparison can be drawn between Norton's weak anthropocentrism and what Burms calls metaphysical anthropocentrism, namely, a theory according to which nature is understood as a meaningful context that speaks to humans (Burms in Drenthen 2011, 152-154). However, such a comparison is not an object of investigation in this article. 
and vice versa. For instance, so-called empathic concern is what many philosophers and psychologists describe as a matter of sympathy (Maibom 2014, 1-2). Secondly, when by addressees of empathy and sympathy we understand not only humans, but also representatives of other species, the problem is whether or not the one who feels empathy or sympathy towards others is able to gain an adequate knowledge of the others' situation, the others' feelings and their motivation in a moral sense.

Against the background of the aforementioned specifications, by empathy I understand (affective) empathy according to which S empathizes with O's experience of emotion $E$ in $C$ if $S$ feels $E$ for $O$ as a result of believing or perceiving that $O$ feels $\mathrm{E}$, or of imagining being in $\mathrm{C}$. In turn, by sympathy I understand the following case: $\mathrm{S}$ sympathizes with $\mathrm{O}$ when $\mathrm{S}$ feels sad for $\mathrm{O}$ as a result of believing or perceiving that something bad has happened to $\mathrm{O}$, or $\mathrm{S}$ feels happy for $\mathrm{O}$ as a result of believing or perceiving that something good has happened to O (Sober \& Willson 1998; Maibom 2012; Maibom 2014, 3). Comparing and contrasting the moral consequences of showing empathy and sympathy is carried out for the purposes of demonstrating that sympathizing, understood as a matter of feeling corresponding sadness or joy, is not a sufficient condition for successfully applying the principle of "advocatory" representation to the others who are not like the ones feeling sympathy.

As a particular type of empathy, which has both advantages and disadvantages when addressed to non-human beings, I point out the so-called proto-sympathetic empathy. It is called "proto-sympathetic" because "it brings the other's relation to his situation into view in way that can engage sympathy on his behalf" (Darwall 1998, 271).

\subsection{Structure}

In Section 2 of this article, I briefly examine why mapping (un)common worlds into one (un)common space is unrealizable both from the perspective of radical anthropocentrism and from that of radical eco-centrism, since both perspectives support, although in different ways, the justification of the center-periphery dichotomy which is not axiologically neutral. In Section 3, I raise a hypothesis that one can overcome the extremes of both radical anthropocentrism and radical eco-centrism by introducing the principle of ethical gradualism. The latter is examined as a principle which makes room for showing how humans, by being moral agents, can morally address those beings which cannot make moral decisions by themselves. In turn, in Section 3.1., I analyze the origin of some moral problems, regarding the distinction between so-called biographical and biological lives, which necessitate the application of ethical gradualism into an interspe- 
cies context. As a follow-up issue, which is explored in the next two sections, 3.2 and 4 , I examine the impact of the development of both empathy and sympathy on the application of ethical gradualism when humans interact with other beings. Specifically, in Section 4.1, I elaborate upon the methodological advantages and disadvantages of showing proto-sympathetic empathy towards non-human beings.

\section{Mapping Space from the Perspectives of Radical Anthropocentrism and Radical Eco-centrism}

Paradoxically enough, both radical anthropocentrism and radical eco-centrism support the idea of one common world, although they derive from mutually exclusive assumptions regarding the subjects who map its space. In the case of radical anthropocentrism, the space of common world is exhausted by humans. It is mapped by humans for humans, while in radical eco-centrism the common world is considered as being mapped by nature as a homogenous subject for nature alone. In both cases, the relation between a common world and uncommon worlds is set on the principle of exclusion. The world which is recognized as a common world gains the privilege of calling itself center, while the rest - that which constitutes uncommon worlds, if any - is coined as periphery.

However, looking for a solution to the aforementioned extremes (arguing for either radical anthropocentrism or radical eco-centrism) would not give us any hint on how to proceed with mapping space as a space of co-existence, which assumes the existence of many different, even contradictory worlds. This is due to the fact that neither proclaiming the end of nature nor proclaiming the end of humans can solve the problems of interspecies coexistence.

\section{The Role of Ethical Gradualism}

Why should we choose the principle of ethical gradualism? I raise the hypothesis that, by adopting the principle of ethical gradualism, humans can reveal that center is not good by default nor is periphery by default bad. One should also keep in mind that "good" and "bad" have some different connotations when evaluated from the perspectives of radical anthropocentrism and radical eco-centrism. In turn, rethinking the role of ethical gradualism in fulfilling some scenarios of co-existence is encouraged by the presumption that living in the same space is a matter not only of living with but also without others, which is not an axiologically neutral choice or an axiologically neutral 
lack of choice either. A similar conclusion applies to living in different spaces because we can live with others even when they do not live in one and the same world with us. The situation is complicated by the additional requirements of how to live in one and the same or in different spaces, when we and others live in different worlds.

Furthermore, the scenario of co-existing in one space full of different worlds shows that, similar to the way in which we cannot rely upon the center-periphery dichotomy, we can no longer rely upon the common-uncommon one either. This is due to the fact that the latter dichotomy is no longer recognizable as based upon the assumption that spatial (physical) proximity leads to social and moral proximity by default.

Judging by the aforementioned investigations, I raise a hypothesis that adopting the principle of ethical gradualism requires an enrichment of both the scope and the criteria for mapping by adding the differentiated criterion of sharing, with respect to the process of co-existence. It is the diverse conceptualizations of the idea of sharing that determine the understanding of whether or not space is mapped from the perspective of being among the others at the expense of being with them or the other way around.

Regarding the process of co-existence, the question is whether or not we have internalized the engagement with our concern for others, ${ }^{2}$ especially when these others are not like us. The dilemma gets even more complicated when the requirement for sharing space affects how to re-map this space by making moral engagements on the behalf of others, when the latter could never become moral agents. In other words, the question is how - since morality is a human "invention" - humans can provide moral treatment to representatives of organic and non-organic nature who could never exert moral agency by themselves.

Last but not least, the necessity of clarifying the aspects of ethical gradualism is traceable also on the level of human agency, because not all humans are capable (as is understood in the broad sense of the term) ${ }^{3}$ of being moral agents and moral discussants either. ${ }^{4}$ An additional difficulty arises from whether or not co-existence can be guaranteed by recognizing and respecting vital and non-vital needs of all beings involved.

2 Ethics "is not just about being-in but also about being-with" (Zylinska 2014, 91).

3 For instance, the groups of babies, those having intellectual disability etc. cannot be noncontradictorily included into the groups of moral agents and moral discussants.

4 For the definitions of moral agents and moral discussants, as well as the possible extrapolations of the concept of moral subjects to particular groups of animals, see Skirbekk 1994, 115-116. 


\subsection{Some Reasons for Applying Ethical Gradualism into an Interspecies Context}

For the purposes of revealing the possibilities for cultivating moral sensitivity towards non-human beings, I suggest analyzing how adopting the principle of ethical gradualism can contribute to going beyond the dilemmas of what one should do as a moral agent, when some biological and biographical lives (Rachels 1990, 208-223) are at stake. In this context, I argue that the distinction between biological and biographical lives is only a necessary condition for denying the either-or way of thinking. Even if one accepts that some beings have only biological lives, it does not follow that we can neglect their vital needs, even when these beings cannot articulate them at all.

Tracking the difference between biological and biographical lives in practice shows that - in most cases - both of them are at stake. The difficulty in choosing is strengthened by the fact that it is humans who provide the distinction between biological and biographical lives, which means that it may not correspond to the real matter. For instance, when humans are not able to "measure" whether they are dealing with biographical lives or not, ${ }^{5}$ or when these lives are deliberately misrecognized. An additional problem derives from the fact that even if we weigh one biographical life against another biological life, it does not necessarily follow that we, as humans, can decide in favor of the being having a biographical life, especially when two vital needs are at stake.

For instance, how to decide whether or not to kill an endangered animal in order to feed a child, who will otherwise die of starvation. Do we have to save the child since he or she belongs to a species considered more valuable, or to give preference to the value of the animal representing an endangered species, presuming that if this animal loses its life, we will destroy the biospheric equilibrium for good? In both cases, two vital needs regarding survival are at stake.

On the other hand, some additional methodological difficulties arise while evaluating vital needs from the perspectives of individuals and individuals as members of different species respectively. As Alan Holland relevantly argues, "species protection carried out for the sake of one's own well-being may well not yield the well-being which results from species protection carried out for the sake of the species" (Holland 1996, 11n7). This specification makes the process of evaluating whose vital needs matter more complicated, since we should rely upon an incomplete induction when we have

5 The criterion for distinguishing between biological and biographical lives also brings us back to the difficulties deriving from the argument concerning sentient being rights. 
to set a non-critical minimum in respect to vital needs. This presents the problem of defining the future of endangered species.

Deriving from the perspective of incomplete induction in terms of numbers, we cannot state how many representatives of a given species can be sacrificed for the sake of maintaining the vital needs of particular groups of humans. Furthermore, applying incomplete induction to values, we cannot set a clear borderline when and under what circumstances the destroying of the intrinsic value of other beings begins to decisively matter. As one of the reasons for this, I point out that we cannot state the reference relation of value to price once and for all.

Furthermore, I argue that some problems triggered by the distinction between biographical and biological lives can be solved by making ethical gradualism have precautionary functions: firstly, to keep choosing without neglecting the role of biological gradualism, since it concerns vital needs of survival (i.e. to avoid arguing that one's biographical life is independent of one's biological life) and secondly, to maintain the diversity of choices without reaching the extremes of either-or (namely, choosing either biographical or biological life as the life which matters more than the other).

\subsection{The Contribution of Empathy to Building Ethical Gradualism}

In this context, the axiological aspects of the process of mapping space can be outlined by analyzing how the principle of ethical gradualism can be enriched with that of empathy, which is understood as a process of "being in someone else's shoes". ${ }^{6}$ Such a methodological shift points towards the necessity of rethinking the intersection of common and uncommon worlds into one (un)common space. I argue that while sympathy, when recognized as a process of co-feeling the problems of otherness, ${ }^{7}$ makes possible to appeal for co-existing in some common worlds, adopting the principle of ethical gradualism - when coupled with a particular type of empathy - can contribute to making a step forward. It can benefit the cultivation of our sensitivity towards otherness even when others are not close to us in spatial, emotional, moral and social senses. One of the main methodological reasons for enriching the principle of co-feeling is that it does not necessarily follow that by co-experiencing one view point we will feel obliged to understand this respective point of view.

6 See Johnson 1993, 200.

7 Regarding the way sympathy displays "a special type of empathy", as well as how both sympathy and empathy refer, although in a different manner, to the phenomenon of "stepping into another's shoes", see Chismar 1988, 257, 263-264. 
Therefore, the problem is how we, as humans, can avoid both radical anthropocentrism and radical eco-centrism, being aware of the impossibility of thinking about morality in inhuman terms. On a macro-methodological level, the role of ethical gradualism is sought in building moderate ethical anthropocentrism to provide a broad - in the sense of being optimally applied to its addressees - moral engagement, which respects the vital needs of the particular moral subjects, whether humans or representatives of other species.

Judging by the aforementioned investigations, I propose that adopting the principle of ethical gradualism for clarifying what it means to "be in someone else's shoes" can provide us with the possibility to expand the group of empathic addressees with those towards whom we cannot express co-feelings, but whose vital needs matter. Thus, empathy would make room for cultivating so-called conflict sensitivity (Deigh 1995) and give us some good reasons for justifying co-existence as a matter of successfully co-habiting (un)common worlds. From the perspective of mapping, I argue that mapping (un)common worlds into one (un)common space can be exemplified by extrapolating the formula of empathy to Biosphere, namely, by analyzing What does it mean to be in Biosphere's shoes? in one space mapped on the principle of looking for unity without uniformity.

\section{The Role of Empathy vs. the Role of Sympathy}

Certainly, the question What does it mean to be in Biosphere's shoes? should be interpreted as something more than just an impressive metaphor. Adopting such an approach contributes to disenchanting the general understanding of the feeling of sympathy. The latter is grounded in the double-bind presumption that the more we co-experience, the bigger our moral commitment becomes. Furthermore, some humans as moral agents used to believe that the act of co-experience is a sufficient criterion for being moral insofar as it is both intensive and affective.

In turn, developing the role of empathic engagement as a concern with others for their own sake can provide us with some new alternatives in the process of investigation, regardless of the fact that empathy is also determined by humans as moral agents. For instance, if co-experience is conceptualized as other-oriented desire, by cultivating a particular type of empathy it could be extrapolated to care, understood as an elaborated concern for the other. ${ }^{8}$ Thus, moral engagement based upon showing

8 Darwall argues that there are significant methodological pitfalls which one faces in defining "desire other-or self-regarding". The way of determining the desires in question should be consid- 
care could be highly valued if, by elaborating the principle of "seeing the world through the eyes of the other", one can realize what it means to see the world "in the light of someone else's view" as being valuable for that someone. Otherwise, remaining only on the level of seeing alone narrows seeing the moral experience of the other by replacing our responsibility with one affective response.

Another methodological restriction deriving from the process of co-feeling is that sympathy is supposed to display a co-feeling with someone else's misfortune or sorrow, which brings us back to the utilitarian dilemmas: from minimizing suffering does not necessarily follow maximizing well-being. In other words, even in the ideal case when feeling sympathy with another's suffering results in a benevolent moral stance to eradicate the origin of this suffering, it still covers a limited spectrum of moral interactions, which do not necessarily guarantee the positive transformation of the noharm principle into the principle of encouraging well-being. That is why justifying the encouragement of well-being requires specifying how this principle can be applied in a non-contradictory manner to the broadest group of addressees, even in cases when the addressants' vital needs contradict vital needs of empathic addressees.

Cultivating sympathy also sets the no-harm principle as an objective with regard to as many beings as possible, but since it derives from the process of co-feeling, it remains unclear how one can reduce and even eradicate that suffering of others, which does not trigger a co-feeling. In this context, we should keep in mind that appealing for empathy does not mean the replacing of co-feeling with cognitive knowledge alone, but implies a certain gradualism. The latter could encourage coupling feeling with understanding so as to restrict encouraging bad moral infinity, namely, that every single need of other beings would be recognized as being vital, or that one would show unrestricted empathy even towards beings which exert immoral agency.

On the other hand, we should be aware that empathy is not a panacea for all moral dilemmas we face, since there are different types of sympathy and empathy, similarly to the fact that moral addressants and moral addressees are not homogeneous categories either. For instance, we should avoid some extreme cases such as sadist empathy (Deigh 1995, 761), where the process of feeling with understanding is triggered by the joy of witnessing someone else's suffering. ${ }^{9}$

ered as a matter of regard or concern for the other person (Darwall 1998, 276): "And what makes something good for someone (self or other), is that it is the object of a rational self- or otherregarding desire. What is primitive is concern for the person" (ibid., 276-277).

9 Among the other problematic types of empathy, one can point out so-called mistaken empathy (Nilsson 2003, 77) and egocentric empathy (Lakoff \& Johnson 1999, 310). 


\subsection{The Role of Proto-Sympathetic Empathy}

Another case concerns the so-called proto-sympathetic empathy, which is described as a particular type of projective empathy, where attention is paid not to the other but to her situation as we imagine she sees it, or as we think she should see it (Darwall 1998, 270). The difference with the general process of sympathy is exemplified by Darwall in the following cases: (a) imagine what someone would feel if he were to lose his only child and (b) imagine what it would be like for that person to feel that way (ibid.). The first case involves simulating someone in the imagined circumstances in order "to identify what feelings the situation would apparently warrant when so viewed" (ibid.). It does not assume paying attention at all to what it would be like for the person to have those feelings or to suffer that loss. "To comply with the second request, however, one would have to simulate, not just a person with the relevant feelings, but someone conscious of his feelings..." (ibid.). Darwall calls empathy of this latter case proto-sympathetic empathy - "proto-sympathetic" because it brings the other's relation to his situation into view in a way that can engage sympathy on his behalf. Proto-sympathetic empathy assumes developing projective empathy, "but goes beyond it in not being felt entirely as from the other's standpoint (or, at least, not without projected self-consciousness)" (ibid., 271).

However, extrapolating the role of proto-sympathetic empathy to interspecies context raises the difficulty that providing a projection should be preceded by the assumption that by having full awareness, projective self-consciousness is possible. Going back to Darwall's example with the grieving parent, showing proto-sympathetic empathy would mean that a grieving animal parent is conscious of his or her feelings and that the way a human parent grieves is similar to the way an animal parent grieves. Another difficulty is derived from the fact that grieving human and animal parents are not homogeneous categories. This in turn means that drawing such correspondences is conducted with an immense degree of uncertainty based upon some behaviorist similarities which expand upon the principle of analogy to moral similarities.

\section{Conclusion}

One of the main challenges in the era of the Anthropocene, namely, how to live in one (un)common space, where there are many (un)common worlds available is already formulated, although in a different manner, in the Brundtland report Our Common Future (1987). According to the report, we have one Earth but many worlds (Brundtland 
Report 1987, 28): "The Earth is one but the world is not" (ibid.). Even this conceptualization of the problem demonstrates that arguing for a plurality in an (un)common space is not an axiologically neutral issue since it assumes specifying how to connect multiple worlds to one Earth.

That is why I argue that adopting the principle of ethical gradualism could open up some new perspectives of interacting with others by going beyond the paradigm of choosing either...or and by avoiding the difficulties in choosing either radical anthropocentrism or radical eco-centrism. Otherwise, paradoxically enough, radical anthropocentrism and radical eco-centrism would favor building one space, similar in its absolutist embodiments, a space where the idea of being commonly shared will be grounded in the principle of exclusion. Thus, common worlds will be justified as worlds excluding either humans or other beings depending on what subjects are recognized as the ones deciding on others' behalf.

In turn, adopting the principle of ethical gradualism can provide us with some solutions regarding how to avoid choosing either biological or biographical life, especially when we should choose between two biographical lives by introducing the problem of conflict sensitivity, as evaluated from the diverse net of configurations between vital and non-vital needs. Judging by the aforementioned investigations, I draw the conclusion that it is cultivation of sensitivity to the mode of living with others that can contribute humans to be morally engaged with moral treatment of beings which could never develop moral agency.

As a type of empathy which brings to light both some benefits and restrictions regarding the application of the principle of ethical gradualism, I pointed out the socalled proto-sympathetic empathy. Among its methodological contributions, I outlined the way in which it enriches the process of co-feeling with a particular moral engagement on others' behalf. In turn, among the most serious problems in applying protosympathetic empathy to other species, I emphasized that we do not have unquestionable proofs whether or not these species are conscious about the situation they have fallen into, as well as whether or not human awareness of this situation corresponds to other species' awareness in both epistemological and moral terms. That is why I draw the conclusion that the aforementioned difficulties are similar to these triggered by the argument of "sentient being rights". Furthermore, the difficulties regarding protosympathetic empathy also affect whether or not the corresponding awareness can be witnessed not only on individual but also on a collective level, which complicates the evaluation of confronting vital needs.

Extrapolating the debate about how to live with others on a macro-methodolog- 
ical level would mean that both forms of radicalism, namely, radical anthropocentrism and radical eco-centrism, could be examined as demonstrations of hubris in mapping space of unity with uniformity, where peaceful co-existence excludes conflict sensitivity by default. By arguing that co-existence requires having living condition whereupon human condition is only a part, one should appeal for the recognition of the (un) common space of (un)common worlds, not as a no man's land, but as everyone's land, whereupon bad moral infinity is replaced with the sense of belonging to feel at home in the Biosphere.

\section{REFERENCES}

Begley, Ed. 2009. Guide to Sustainable Living. Learning to Conserve Resources and Manage an Eco-conscious Life. New York: Clarkson Potter Publishers.

Brundtland Report. Our Common Future: Report of the World Commission on Environment and Development. 1987. Oxford: Oxford University Press. http://www.un-documents.net/our-common-future.pdf.

Chismar, Douglas. 1988. "Empathy and Sympathy: The Important Difference." Journal of Value Inquiry 22, no. 4: 257-266.

Darwall, Stephen. 1998. "Empathy, Sympathy, Care.” Philosophical Studies, 89, no. 2-3: 261-282.

Deigh, John. 1995. "Empathy and Universalizability." Ethics, 105, no. 4: 743-763.

Drenthen, Martin. 2011. "Ecocentrism as Anthropocentrism." Ethics, Policy and Environment, vol. 14, no. 2: 151-154.

Francis, Ronald, Erminioi Gius, and Romina Coin. 2004. "Ethical Gradualism: A Practical Approach." Australian Journal of Professional and Applied Ethics, 5, no. 1: 25-34.

Francis, Ronald, and Guy Murfey. 2015. Global Business Ethics: Responsible Decision Making in an International Context. London: Kogan Page.

Holland, Alan. 1996. "Getting the Measure of Sustainability." In Four Essays on Ecological Economics. The Thingmount Working Paper Series on the Philosophy of Conservation, edited by Alan Holland and Jeremy Roxbee Cox, 4-16. Lancaster University: BANC. http://www.lancaster.ac.uk/users/philosophy/awaymave/onlineresources/getting\%20the\%20measure\%20of\%20sustainability\%20_a\%20holland_.pdf.

Johnson, Mark. 1993. Moral Imagination. Implications of Cognitive Science for Ethics. Chicago: Chicago University Press.

Lakoff, George, and Mark Johnson. 1999. Philosophy in the Flesh: The Embodied Mind and Its Challenge to Western Thought. New York: Basic Books. 
Liddick, Donald. 2006. Eco-terrorism: Radical Environmental and Animal Liberation Movements. Connecticut: Praeger Publishers.

Maibom, Heidi. 2012. "The Many Faces of Empathy and Their Relation to Prosocial Action and Aggression Inhibition." Wiley Interdisciplinary Reviews: Cognitive Science (WIRE), 3: 253-263.

Maibom, Heidi. 2014. Empathy and Morality. Oxford: Oxford University Press.

Nilsson, Peter. 2003. "Empathy and Emotion: On the Notion of Empathy as Emotional Sharing." PhD diss., Umeå University.

Norton, Bryan. 1984. "Environmental Ethics and Weak Anthropocentrism." Environmental Ethics, vol. 6, no. 2: 131-148.

Rachels, James. 1990. Created from Animals. The Moral Implications of Darwinism. Oxford: Oxford University Press.

Skirbekk, Gunnar. 1994. "Ethical Gradualism, beyond Anthropocentrism and Biocentrism?" In The Notion of Sustainability and Its Normative Implications, edited by Gunnar Skirbekk, 79-126, Trøgstad: Scandinavian University Press.

Sober, Elliott, and David Willson. 1998. Unto Others: The Evolution and Psychology of Unselfish Behavior. Cambridge, MA: Harvard University Press.

Zylinska, Joanna. 2014. Minimal Ethics for the Anthropocene. Ann Arbor, MI: Open Humanities Press. 